\title{
Breve história da edição crítica das obras de Karl Marx*
}

\author{
A bistorical critical edition \\ of the works of Karl Marx
}

HUGO E. A. DA GAMA CERQUEIRA**

\begin{abstract}
RESUMO: Este artigo discute as tentativas de publicar uma edição histórico-crítica das obras de Karl Marx, o Marx-Engels Gesamtausgabe (MEGA): a primeira, que foi liderada por David Riazanov na décadas de 1920 e 1930, e o segundo, a MEGA2, projeto que começou na década de 1970 e ainda está em curso de publicação. O artigo apresenta essas duas edições e discute o seu impacto sobre a interpretação do pensamento econômico e filosófico de Marx. PALAVRAS-CHAVE: Karl Marx (1881-1883); Friedrich Engels (1820-1895); MEGA; marxologia.
\end{abstract}

ABSTRACT: This paper discusses the attempts to publish a historical-critical edition of the works of Karl Marx, the Marx-Engels Gesamtausgabe (MEGA): the first one, which was led by David Riazanov in the 1920s and 1930s, and the second one, the MEGA2 project which begun in the 1970s and is still in course of publication. The paper presents these two editions and discusses their impact on the interpretation of Marx's economic and philosophical thought.

KEYWORDS: Karl Marx (1818-1883); Friedrich Engels (1820-1895); MEGA; marxology. JEL Classification: A31; B14; B24.

“Tudo que sei é que eu não sou um marxista."1 "In a book published in the early 1980s I came across a cartoon. It showed a man meeting Karl Marx on a cloud in heaven. The man says to Marx 'I've read your book.' Marx replies: 'Oh really? And how does it end?”2

\footnotetext{
* A pesquisa que deu origem a este artigo contou com o apoio do CNPq.

* Professor do Centro de Desenvolvimento e Planejamento da Universidade Federal de Minas Gerais, Cedeplar/UFMG. E-mail: hcerqueira@ufmg.br. Submetido: 4/junho/2014; Aprovado: 7/julho/2014.

${ }^{1}$ Frase atribuída a Marx por Engels, em carta dirigida a Conrad Schmidt datada de 05/08/1890.

${ }^{2}$ Contado por Bellofiore (1999, p. 43).
} 


\section{INTRODUÇÃO}

No último século e meio, a obra de Karl Marx foi lida por pesquisadores e estudiosos das mais diferentes disciplinas e em toda parte do mundo. É difícil lembrar algum outro pensador que tenha sido tão influente nesse período. Grande parte dos conceitos que empregamos para pensar o mundo contemporâneo deriva direta ou indiretamente de seus trabalhos. Suas ideias incidiram sobre todo o espectro das ciências sociais e, até recentemente, o marxismo, doutrina inspirada em sua obra, era reivindicado por governos que dirigiam um terço da humanidade (Hobsbawm, 2011, p. 311).

Se Marx foi amplamente lido, é preciso notar, por outro lado, que a recepção de sua obra comporta numerosos problemas, distorções e, até mesmo, paradoxos (Thomas, 1991). Em primeiro lugar, o fato de que suas ideias tenham invadido os currículos de várias disciplinas acadêmicas não deve nos fazer esquecer a relativa marginalização de sua influência justamente naqueles campos em que ele teria mais a nos ensinar, a começar pela economia, mas também a filosofia e a política. Em segundo lugar, nos países em que o nome de Marx foi venerado e o marxismo se constituiu em ideologia oficial, a leitura de suas obras ficou restrita a um punhado de estudiosos ligados a instituições pouco conhecidas. Fora delas, o que prevaleceu foi o ensino de alguma versão simplificada e monolítica das ideias de Marx, construída de modo a proporcionar justificativas para as práticas políticas dos regimes vigentes. Finalmente, seguidores e adversários de Marx estabeleceram uma continuidade direta e estrita entre suas ideias e aquelas que povoaram o marxismo em suas diferentes versões. Desse modo, as diferenças que poderiam existir - e, certamente, existem - entre os conceitos marxianos e as ideias marxistas foram deixadas em segundo plano e terminaram apagadas.

Com efeito, se tomarmos por marxianos os juízos e conceitos que podemos atribuir com segurança ao próprio Marx e por marxistas as ideias que são consideradas pela maioria como estando de acordo com o seu legado intelectual, então é fácil ver que nem tudo que passa por marxista é marxiano: as teorias do imperialismo, por exemplo, pertencem muito mais a Lenin, Hilferding ou Bukharin que ao próprio Marx. Por outro lado - e mesmo que isso soe mais estranho ou até paradoxal -, não é menos verdade que nem tudo que é marxiano pode ser considerado marxista, quando mais não fosse, pela simples razão de que o marxismo se desenvolveu numa época em que o conhecimento dos escritos de Marx era repleto de lacunas e, por isso mesmo, parcial e inadequado (Thomas, 1991, pp. 25-6).

Foi assim, por exemplo, que a doutrina do "materialismo histórico" - expressão jamais empregada por Marx - foi formulada nas últimas décadas do século XIX e nas primeiras do século XX por autores como Plekhanov, Mehring e Kautsky, muito antes que o manuscrito de A Ideologia Alemã fosse publicado. Essa doutrina, por sua vez, influenciou decisivamente a maneira como o manuscrito de Marx e Engels foi lido e interpretado: como um texto no qual se encontraria, pela primeira vez, uma versão mais ou menos acabada do assim chamado "materialismo histórico". 
$\mathrm{Na}$ mesma direção, o descompasso entre o marxismo e algumas ideias de Marx permite compreender a tensão provocada pela publicação de obras como os $\mathrm{Ma}$ nuscritos Econômico-Filosóficos e os Grundrisse der Kritik der politischen Ökonomie. Ao virem à luz, esses textos desafiaram as interpretações convencionais sobre a crítica da economia política e deram origem a longas controvérsias em que, muitas vezes, foram reduzidos à condição de obras da juventude, anteriores à maturidade e incompatíveis com o sentido já estabelecido da elaboração teórica de Marx que, por sua vez, não se admitia que fosse posto em questão.

Por essa razão - pelo fato de que o marxismo se constituiu antes mesmo que a maioria dos textos de Marx fosse conhecida - a compreensão da recepção da obra de Marx requer que um entendimento seguro do movimento de edição e publicação de cada um de seus textos. Por sua vez, o conhecimento desses dois processos - da maneira como as obras de Marx vieram a público e do modo como foram lidas - pode remover obstáculos e sugerir caminhos para uma releitura desses textos em nova chave e para uma reinterpretação do pensamento de Marx, agora livre das funções ideológicas que pesaram sobre ele no passado.

É o que procuramos mostrar no artigo que vai ser lido. Ele está organizado em três partes, além desta introdução e de uma breve conclusão. A primeira seção discute as tentativas iniciais de edição das obras de Marx e Engels até o final abrupto da primeira Marx-Engels-Gesamtausgabe (MEGA). A segunda aborda brevemente a edição da Marx Engels Werke e apresenta o projeto da nova MEGA2. A terceira seção analisa algumas repercussões da MEGA2 para a interpretação de textos consagrados de Marx.

\section{PRIMEIROS ESFORÇOS E A MEGA}

Passados 130 anos da morte de Karl Marx, parte significativa de seus escritos permanece inédita e, desse modo, inacessível e desconhecida para a imensa maioria dos pesquisadores de sua obra. ${ }^{3}$ Com efeito, o problema de como tornar públicos estes manuscritos remonta ao longo e penoso esforço de Engels para editar e publicar a quarta edição do livro I de O Capital - lançada em 1890 e tida por muito tempo como a edição padrão ou "definitiva" - e de compor, a partir dos rascunhos deixados por Marx, os livros II e III daquela obra, lançados em 1885 e 1894.

No final do século XIX, a ascensão do movimento socialista despertou um interesse crescente pelos trabalhos de Marx e Engels, o que motivou o surgimento de traduções de textos clássicos, como o Manifesto Comunista, em diversas línguas. O mesmo movimento deu origem à tentativa de Engels de publicar de modo sistemático uma parte expressiva de seus trabalhos nas línguas em que foram compostas, o que ensejou a reedição de textos há muito esgotados - como Miséria da filo-

\footnotetext{
${ }^{3}$ Trechos dessa seção reproduzem o texto de trabalhos anteriores do autor (Cerqueira, 2011; Paula et al., 2013).
} 
sofia e O 18 Brumário -, a publicação de textos que Marx deixara inéditos - como A crítica de Gotha e os dois livros d' O Capital - e, finalmente, a publicação de novos escritos de Engels - como o Anti-Dühring e A origem da família, da propriedade privada e do Estado. Porém, não havia ainda a intenção de publicar o conjunto completo dos escritos de Marx, nem mesmo o de fazer sua edição de modo a permitir reconstituir a gênese e o desenvolvimento de seu pensamento. Os volumes editados por Engels visavam, sobretudo, tornar acessível aos militantes socialistas um conjunto de escritos teóricos que formavam, a seu juízo, uma espécie de corpus acabado da doutrina elaborada por ele e por Marx (Anderson, 2010, p. 247, Hobsbawm, 1983, p. 427).

A ideia de publicar uma edição crítica das obras completas de Marx e Engels remonta ao mês de dezembro de 1910, quando foi discutida por um grupo proeminente de austro-marxistas. O plano da chamada "Edição de Viena", entretanto, não se realizou, seja pelas dificuldades encontradas para financiá-lo, seja pelos problemas decorrentes do início da Primeira Guerra Mundial. Ainda assim, nas duas primeiras décadas do século XX o conjunto dos textos de Marx e Engels disponíveis para leitura foi ampliado pelos esforços de estudiosos como Karl Kautsky, que publicou entre 1905 e 1910 a parte dos manuscritos de 1861-63 conhecida como Teorias da mais-valia, Franz Mehring, que em 1902 editou uma coletânea de textos de Marx e Engels dos anos 1841-50 (além de cartas de 1849-62) e, finalmente, David Riazanov, que publicou dois volumes reunindo os artigos escritos por Marx e Engels nos anos 1850 para jornais como o New York Tribune e o People's Paper (Rojhan, 1998, p. 3; Hecker, 2010, p. 282). ${ }^{4}$

Naquela altura, Riazanov já era um dos maiores, senão o maior conhecedor do legado literário de Marx. Os contatos que estabeleceu com Auguste Bebel e Kautsky asseguraram-lhe o acesso aos manuscritos de Marx e Engels, que estavam de posse do Partido Social-Democrata Alemão (SPD), bem como aos textos de Marx preservados por Laura Lafargue. Com a Revolução Russa de 1917, ele teve a oportunidade de dar início à primeira tentativa de realizar uma edição histórico-crítica das obras completas de Marx e Engels, a Marx-Engels-Gesamtausgabe (MEGA). Tendo sido encarregado por Lenin de fundar e dirigir o Instituto Marx-Engels, em Moscou, Riazanov obteve um significativo apoio material e financeiro para sua organização, bem como independência para recrutar o seu staff entre os especialistas disponíveis. Montou uma ampla rede de correspondentes na Europa e estabeleceu uma intensa colaboração com o Institut für Sozialforschung (Institu-

\footnotetext{
${ }^{4}$ Kautsky, Karl (ed.). Theorien über den Mehrwert aus dem nachgelassenen Manuskript "Zur Kritik der politischen Ökonomie" von Karl Marx. (Volume 1: Die Anfänge der Theorie vom Merhrwert bis Adam Smith; Volume 2. David Ricardo; Volume 3. Von Ricardo zur Vulgärökonomie) Stuttgart: J.H.W. Dietz, 1905-1910. Mehring, Franz (org.), Aus dem literarischen Nachlass von Karl Marx, Friedrich Engels, und Ferdinand Lassalle, 4 volumes, Stuttgart: J. H. W. Dietz Nachf, 1902. Riazanov, David (org.), Gesammelte Schriften von Karl Marx und Friedrich Engels, 1852 bis 1862.2 volumes, Stuttgart: J.H.W. Dietz Nachf, 1917. Edições facsimilares desses livros podem ser encontradas em meio eletrônico em <http://www. archive.org/>.
} 
to de Pesquisa Social), de Frankfurt, que à época estava sob a direção de Carl Grünberg. Desse modo, ele pôde reunir o material necessário para dar início à edição da MEGA: a aquisição de originais ou a realização de fotocópias das cartas, manuscritos e volumes existentes nos arquivos do SPD em Berlim.

O plano editorial da primeira MEGA previu o lançamento de 42 volumes divididos em quatro partes ou seções. A primeira seção, com 17 volumes, deveria reunir os escritos de Marx e Engels com exceção daqueles relacionados a O Capital, que seriam objeto dos 13 volumes da segunda seção. A terceira parte deveria abrigar toda a correspondência de Marx e Engels, incluindo a correspondência entre os dois autores, mas também suas cartas a Lassalle, Weydemeyer, Kugelmann, Freiligrath e outros. Finalmente, o plano original previa também uma quarta parte composta de dois volumes contendo índices temáticos e de nomes.

Do total planejado, somente 11 volumes chegaram a aparecer entre $1927 \mathrm{e}$ 1935 (ver o Quadro I). Mesmo assim, ampliaram significativamente o conjunto de trabalhos disponíveis ao incluir as primeiras edições de textos como os Manuscritos Econômico-Filosóficos e A Ideologia Alemã, que tiveram um impacto decisivo e prolongado nos debates sobre a interpretação do pensamento de Marx. Aos 11 volumes da coleção podem ser ainda acrescentados um volume especial com o Anti-Dühring de Engels, publicado em 1935, e os dois volumes com os manuscritos de Marx de 1857-58, os Grundrisse der Kritik der politischen Ökonomie, lançados em 1939 e 1941 no mesmo formato dos livros editados pela MEGA (Cerqueira, 2010, pp. 208-12).

Por outro lado, é importante notar que, apesar dos rigorosos critérios filológicos e editoriais adotados por Riazanov e sua equipe, o projeto da MEGA não previa a publicação de uma parte significativa dos manuscritos de Marx, composta por seus cadernos de excertos (Exzerpthefte). Estes últimos reúnem longos trechos dos trabalhos que Marx estudou ao longo de sua vida, extratos que ele copiou, resumiu e comentou em dezenas de cadernos redigidos para seu uso pessoal. Num relatório escrito em 1923, Riazanov já mencionava a existência desses cadernos de anotações que, a seu juízo, seriam úteis, sobretudo, aos biógrafos de Marx, mas cuja publicação não se cogitou no projeto da MEGA. ${ }^{5}$ De fato, a existência de alguns desses cadernos e a natureza dos temas ali tratados chegaram a causar-lhe surpresa:

"If in 1881-82 he [i.e., Marx] lost his ability for intensive, independent, intellectual creation, he nevertheless never lost the ability for research. Sometimes, in reconsidering these Notebooks, the question arises: Why did he waste so much time on this systematic, fundamental summary, or expend so much labor as he spent as late as the year 1881, on one

\footnotetext{
${ }^{5}$ A exceção coube a "alguns cadernos de matemática” de Marx, que foram editados nos anos 1920 por um jovem matemático alemão, Julius Gumbel, mas que só foram publicados em 1968. Ver, a propósito, Alcouffe e Wells (2009, pp. 1-12).
} 
basic book on geology, summarizing it chapter by chapter. In the $63^{\text {rd }}$ year of his life - that is inexcusable pedantry. Here is another example: he received, in 1878, a copy of Morgan's work. On 98 pages of his very miniscule handwriting (you should know that a single page of his is the equivalent of a minimum of 2.2 pages of print) he makes a detailed summary of Morgan. In such manner does the old Marx work" (Riazanov apud Anderson, 2010, pp. 248-9).

A verdade é que, ao longo do tempo, a posição de Riazanov a respeito daqueles cadernos parece ter evoluído. Num texto de 1929 ele reconheceu que, dado o método de trabalho adotado por Marx, era por vezes difícil distinguir o que deveria ser considerado um caderno de extratos daquilo que poderia ser considerado um caderno de "trabalhos preparatórios". A razão é que, mesmo em cadernos que praticamente não contêm comentários do próprio Marx, os trechos recolhidos estão tão estreitamente agrupados em torno de um determinado problema que deveriam ser considerados um "trabalho preparatório" para uma pesquisa já prevista. Por outro lado, dizia, em muitos cadernos os excertos estão entremeados por observações de Marx e, em outros, ele desenvolve longas digressões que já são uma expressão de seu pensamento. Consciente de que o estudo da gênese da crítica da economia política não poderia prescindir do exame destes cadernos, Riazanov expressou sua esperança de que o progresso da pesquisa histórico-filológica sobre a obra de Marx seria tal que, em pouco tempo, far-se-ia sentir a necessidade de uma edição integral dos cadernos de excertos (Hecker, 2002, pp. 50-1).

Lamentavelmente, o fato é que essa expectativa e o próprio esforço editorial da MEGA sucumbiram nos anos 1930, vítimas do stalinismo e do nazismo, que adiaram indeterminadamente a possibilidade de ver concluída uma edição completa das obras de Marx e Engels. Em 1931, Riazanov foi preso e deposto da direção do Instituto Marx-Engels. A direção do Instituto, submetida a partir de então ao controle do Partido Comunista, foi confiada a Vladimir Adoratskij e boa parte do seu staff de pesquisadores foi demitida. A posse de Adoratskij representou uma inflexão na trajetória do IME, cuja missão deixou de ser primordialmente a pesquisa e concentrou-se nas tarefas associadas a educação e propaganda política, desenvolvidas sob a direção do Partido. Quanto ao trabalho editorial, a prioridade passou à publicação da Sochinenija, a edição em russo das obras de Marx e Engels, que foi publicada em 28 volumes (33 tomos) lançados entre 1928 e 1947. Nesta última, bem como nos volumes da MEGA lançados a partir de 1931, as introduções e notas ganharam um tom muito diverso daquele presente nos volumes editados por Riazanov. Mais preocupadas em afirmar o marxismo-leninismo e em mostrar uma suposta coerência entre os textos de Marx e Engels e as concepções dominantes no período stalinista, elas deixaram em segundo plano a abordagem histórico-crítica adotada nos volumes iniciais. Além disso, a preocupação de Riazanov em assegurar uma reprodução tão fiel quanto possível do conteúdo dos manuscritos deu lugar a distorções e manipulações arbitrárias. Finalmente, a ascensão do nazismo provocou a emigração e a dispersão da rede de pesquisadores colaboradores 
Abt. 1. Sämtliche Werke und Schriften mit ausnabme des Kapitals [Obras e escritos completos, com exceção d'O Capital]

Bd. 1. Karl Marx. Werke und Schriften bis Anfang 1844 nebst Briefen und Dokumenten [Obras e escritos até o início de 1844, juntamente com cartas e documentos]. Hrsg. von D. Rjazanov. Halbbd. 1. Werke und Schriften. Unveränd. Neudr. d. Ausg. Frankfurt/M., 1927. LXXXIV, 626 S. : mit Abb.

Bd. 1. Karl Marx. Werke und Schriften bis Anfang 1844 nebst Briefen und Dokumenten [Obras e escritos até o início de 1844, juntamente com cartas e documentos]. Hrsg. von D. Rjazanov. Halbbd. 2., Jugendarbeiten, Nachträge, Briefe und Dokumente. Unveränd. Neudr. d. Ausg. Berlin 1929. XLV, 371 S. : mit Abb.

Bd. 2. Friedrich Engels. Werke und Schriften bis Anfang 1844 nebst Briefen und Dokumenten [Obras e escritos até o início de 1844, juntamente com cartas e documentos].. Hrsg. von D. Rjazanov, Unveränd. Neudr. d. Ausg. Berlin, 1930. LXXXII, 691 S. : mit Abb.

Bd. 3. Karl Marx; Friedrich Engels. Die heilige Familie und Schriften von Marx von Anfang 1844 bis Anfang 1845 [A Sagrada Família e escritos de Marx do início de 1844 até o início de 1845]. Hrsg. von V. Adoratskij, Unveränd. Neudr. d. Ausg. Berlin, 1932. XXI, 640 S. : mit Abb.

Bd. 4. Friedrich Engels. Die Lage der arbeitenden Klasse in England und andere Schriften von August 1844 bis Juni 1846 [A situação da classe trabalhadora na Inglaterra e outros escritos de agosto de 1844 a junho de 1846.]. Hrsg. von V. Adoratskij, Unveränd. Neudr. d. Ausg. Berlin, 1932. XX, 558 S. : mit Abb.

Bd. 5. Karl Marx; Friedrich Engels. Die deutsche Ideologie. Kritik d. neuesten dt. Philosophie in ihren Repräsentanten, Feuerbach, B. Bauer u. Stirner u.d. dt. Sozialismus in seinen verschiedenen Propheten 1845-1846 [A ideologia alemã. Crítica da mais recente filosofia alemã em seus representantes, Feuerbach, B. Bauer e Stirner, e do socialismo alemão em seus diferentes profetas. 1845-1846]. Hrsg. von V. Adoratskij, Unveränd. Neudr. d. Ausg. Berlin, 1932. XIX, 706 S. : mit Abb.

Bd. 6. Karl Marx; Friedrich Engels. Werke und Schriften von Mai 1846 bis März 1848 [Obras e escritos de maio de 1846 a março de 1848]. Hrsg. von V. Adoratskij, Unveränd. Neudr. d. Ausg. Moskau/ Leningrad, 1933. XXI, 746 S. : mit Abb.

Bd. 7. Karl Marx; Friedrich Engels. Werke und Schriften von März bis Dezember 1848 [Obras e escritos de março a dezembro de 1848]. Hrsg. von V. Adoratskij, Unveränd. Neudr. d. Ausg. Moskau, 1935. XXII, 768 S. : mit Abb.

Abt. 3. Briefwechsel [Correspondência]

Bd. 1. Der Briefwechsel zwischen Marx und Engels 1844-1853 [A correspondência entre Marx e Engels, 1844-1853]. Hrsg. von D. Rjazanov, Unveränd. Neudr. d. Ausg. Berlin, 1929. L, 539 S. : mit Abb.

Bd. 2. Der Briefwechsel zwischen Marx und Engels 1854-1860 [A correspondência entre Marx e Engels, 1854-1860]. Hrsg. von D. Rjazanov, Unveränd. Neudr. d. Ausg. Berlin, 1930. XXI, 564 S. : mit Abb.

Bd. 3. Der Briefwechsel zwischen Marx und Engels 1861-1867 [A correspondência entre Marx e Engels, 18611867]. Hrsg. von D. Rjazanov, Unveränd. Neudr. d. Ausg. Berlin, 1930. XXIII, 488 S. : mit Abb.

Bd. 4. Der Briefwechsel zwischen Marx und Engels 1868-1883 [A correspondência entre Marx e Engels, 1868-1883]. Hrsg. von V. Adoratskij, Unveränd. Neudr. d. Ausg. Berlin, 1931. XVI, 759 S. : mit Abb.

Volumes associados à MEGA

Sonderbd. Friedrich Engels. Herrn Eugen Dührings Umwälzung der Wissenschaft. Dialektik der Natur. 1873 - 1882 [O Senhor Eugen Dühring revoluciona a ciência. Dialética da natureza. 1873-1882]. Hrsg. von V. Adoratskij. Sonderausg. z. 40. Todestage von Friedrich Engels, Unveränd. Neudr. d. Ausg. Moskau 1935. XLVII, 846 S. : mit Abb.

Karl Marx. Grundrisse der Kritik der politischen Ökonomie (Rohentwurf) 1857-1858 [Fundamentos da crítica da economia política (rascunho) 1857-1858]. Hauptw.. Moskau: Verl. f. fremdsprachige Literatur, 1939. XVI, 764 S. : 5 Taf.

Karl Marx. Grundrisse der Kritik der politischen Ökonomie (Rohentwurf) 1857-1858 [Fundamentos da crítica da economia política (rascunho) 1857-1858]. Anh., 1850-1859. Moskau: Verl. f. fremdsprachige Literatur, 1941. S. 770-1103.

Fonte: Elaborado com base no catálogo da Deutschen Nationalbibliothek. 
do Instituto na Alemanha e contribuiu decisivamente para o fim do projeto editorial da MEGA (Cerqueira, 2010; Takenaga, 2009; Zapata, 1985; Musto, 2007).

\section{A NOVA MEGA}

Foi somente nos anos 1950, especialmente após a morte de Stalin e as reviravoltas políticas que se seguiram, que o espaço tornou a se abrir para que o plano de uma edição crítica voltasse a ser discutido tanto em Moscou como em Berlim. Os problemas associados a essa iniciativa eram muitos, a começar pelos custos elevados do projeto, mas também pelas preocupações de ordem ideológica: o temor de que uma edição desse tipo viesse fragilizar a função primordial dos textos de Marx e Engels para os partidos comunistas e os regimes do Leste Europeu, de servirem de suportes do marxismo-leninismo (Bellofiore e Fineschi, 2009, p. 3; Rojhan, 1998, pp. 3 ss.).

Diante dessas dificuldades, o Instituto de Marxismo-Leninismo de Berlim Oriental deu início a um projeto editorial menos ambicioso: a edição de uma coleção, a Marx Engels Werke (MEW), que totalizaria 41 volumes publicados entre 1956 e 1968. Mesmo não sendo completa, ela se constituiu na edição mais abrangente entre as disponíveis. Rapidamente foi adotada como referência pela maioria dos estudiosos de Marx e serviu de base para traduções em diversas línguas, a começar pela edição japonesa, lançada entre 1959 e 1975, e pela versão inglesa, em 50 volumes, a Marx-Engels Collected Works (MECW), publicada entre 1975 e 2005 (Takenaga, 2009).

No final dos anos 1960, vencida em parte a resistência política, os Institutos de Marxismo-Leninismo (IML) de Moscou e de Berlim deram início aos trabalhos para a edição de uma segunda Marx-Engels-Gesamtausgabe, a MEGA2. Um volume de teste (Probeband) foi lançado em 1972 e, depois de intensas discussões, foram estabelecidos os princípios editoriais que deveriam presidir a nova edição. Ficou decidido que ela deveria ser absolutamente completa, incluindo a íntegra das obras publicadas e dos textos inéditos de Marx e Engels, os cadernos de excertos e notas, bem como as cartas de autoria de terceiros e dirigidas a ambos. Estabeleceu-se ainda que cada material deveria ser transcrito na língua em que fora composto e a ortografia e a pontuação originais deveriam ser preservadas.

Inicialmente previu-se a publicação de 164 volumes. Posteriormente, com as dificuldades de financiamento do projeto, esse número foi revisto para 114 volumes. Cada volume é composto de dois tomos: o primeiro, contendo os textos de Marx e Engels, e o segundo, com o aparato crítico da edição. Os volumes estão distribuídos em quatro seções: a primeira, de textos e rascunhos não relacionados a $O$ Capital; a segunda, com as várias edições de O Capital e o material preparatório relacionado ao livro; a terceira, com a correspondência de (e para) Marx e Engels; e a quarta, contendo os extratos, anotações e notas marginais.

A realização desse projeto dependeria crucialmente da colaboração do Internationaal Instituut voor Sociale Geschiedenis (Instituto Internacional de História 
Social), o IISG, detentor da maior parte dos manuscritos originais de Marx e Engels. ${ }^{6}$ Após a chegada de Hitler ao poder, os papéis que estavam de posse do Partido Social-Democrata Alemão foram levados ao exterior, sendo mais tarde adquiridos por uma companhia seguradora holandesa que os doou ao recém-estabelecido IISG, onde permanecem até hoje (Rojhan, 1998, pp. 3-4).

A coleção Karl Marx / Friedrich Engels Papers deste Instituto abrange um vasto material. ${ }^{7}$ Entre os papéis de Marx, há documentos pessoais e sua correspondência com Engels, Bruno Bauer, Nikolai Danielson, Moses Hess, Ludwig Kugelmann, Ferdinand Lassalle, Wilhelm Liebknecht, Pierre-Joseph Proudhon, Arnold Ruge e muitos outros. A coleção inclui também a correspondência com membros da família, os manuscritos da tese doutoral, partes do manuscrito de Para a crítica da filosofia do direito de Hegel e d'A ideologia alemã, os manuscritos econômicos de 1857-1859 e partes d'O Capital, inclusive as correções e notas adicionais feitas num exemplar impresso com vistas à segunda edição do Livro I. Há ainda quase 200 cadernos de notas com excertos de livros e publicações sobre economia, história, filosofia e outras áreas científicas. Entre os papéis de Engels, além de documentos pessoais e de sua correspondência com Marx, Victor Adler, August Bebel, Eduard Bernstein, Karl Kautsky, Antonio Labriola, Paul Lafargue, Georgij Plekhanov e outras tantas pessoas, há também manuscritos da Dialética da natureza, trabalhos preliminares para a composição do Anti-Dühring, além de notas e excertos de livros e outras publicações. ${ }^{8}$ Todo este material foi inventariado e organizado pelo IISG entre 1959 e 1965, estando dividido em 18 partes identificadas por letras de $A$ a $S$.

De início, o IISG hesitou em apoiar ou participar do projeto da MEGA2, seja pela dimensão da empreitada, seja pelas dúvidas sobre como conduzir uma cooperação com instituições ligadas a partidos políticos, como os IMLs de Moscou e Berlim. Por essa razão, optou por não participar diretamente do projeto editorial, limitando-se a ceder os documentos em sua posse e receber, em contrapartida, acesso aos documentos guardados pelos IMLs. Esse acerto assegurou a viabilidade do projeto, que lançou seus primeiros volumes a partir de 1975. Se é inegável que o aparato crítico dos volumes lançados nesse período ficou marcado por um inconfundível acento ideológico, a natureza acadêmica do projeto foi preservada e, com o tempo, a colaboração entre as instituições e estudiosos tornou-se mais fácil e produtiva, levando a adesão de outros grupos e instituições (Rojhan, 1998, p. 4).

A ampliação do grupo se mostraria crucial para que o projeto da MEGA2 pudesse assegurar sua continuidade mesmo após a dissolução da União Soviética

\footnotetext{
${ }^{6} \mathrm{O}$ restante dos manuscritos encontrava-se, à época, no Instituto de Marxismo-Leninismo de Moscou e, atualmente, no Arquivo Público Russo de História Política e Social.

${ }^{7}$ Além dos documentos adquiridos do SPD, a coleção inclui materiais adquiridos posteriormente pelo IISG.

${ }^{8}$ A coleção inclui ainda material de membros da família de Marx (sua esposa, filhas e outros parentes) e papéis relacionados a Marx e Engels, como panfletos, clippings com resenhas de seus livros e outros artigos, números de revistas contendo seus artigos etc. Para mais detalhes, veja-se a descrição da coleção no site do IISG, na página <http://www.iisg.nl/archives/en/files/m/10760604full.php>.
} 
e a queda dos regimes no Leste Europeu, quando o seu financiamento tornou-se um problema crítico. Em 1990, o IISG, o IML de Moscou, ${ }^{9}$ a Academia de Ciências de Berlim e a Karl Marx Haus (da Fundação Friedrich Ebert) juntaram-se para constituir uma fundação - a Internationale Marx-Engels-Stiftung (IMES), sediada em Amsterdã - que assumiu a direção da MEGA com a responsabilidade de assegurar não apenas os recursos para o trabalho, mas também a uniformidade e a qualidade acadêmica do empreendimento. Para tanto, o projeto foi internacionalizado, com a constituição de grupos de trabalho em diferentes países (o Japão, a França, os EUA, além da Rússia e da Alemanha, entre outros), atuando sem qualquer constrangimento político ou ideológico. O número previsto de volumes foi reduzido, com a eliminação de cerca de 30 volumes da quarta seção que conteriam as notas marginais feitas por Marx e Engels em textos que leram (além da íntegra desses textos)..$^{10}$

Até o presente momento (maio de 2014), 61 volumes da MEGA2 foram publicados. Dos 32 previstos para a primeira seção, 20 estão disponíveis. No que diz respeito à segunda seção (os textos de economia, por assim dizer), o trabalho foi concluído com a publicação dos 15 volumes projetados. Da terceira seção, 14 volumes dos 35 previstos foram publicados. Finalmente, 12 dos 32 volumes planejados para a quarta seção foram lançados até aqui (ver o Quadro II).

Quadro II - Volumes da MEGA2 publicados até maio de 2014

Erste Abteilung: Werke. Artikel. Entwürfe [Primeira seção: obras, artigos e rascunhos]

I/1 M: Werke · Artikel - Literarische Versuche bis März 1843. (Differenz der demokratischen und epikureischen Naturphilosophie, publizistische Arbeiten $u$. a.) [Obras · artigos · ensaios literários até março de 1843 (Diferença entre a filosofia da natureza de Demócrito e Epicuro, trabalhos publicados etc.)], 1975.

I/2 M: Werke · Artikel $\cdot$ Entwürfe. März 1843 bis August 1844. (Zur Kritik der Hegelschen Rechtsphilosophie, Zur Judenfrage, Ökonomisch-philosophische Manuskripte u. a.) [Obras · artigos · rascunhos. De março de 1843 a agosto de 1844 (Para a crítica da Filosofia do Direito de Hegel, Sobre a questão judaica, Manuscritos econômico-filosóficos etc.)] 2., unveränd. Aufl. 2009.

I/3 E: Werke · Artikel · Entwürfe. Bis August 1844 [Obras · artigos · rascunhos. Até agosto de 1844]. 1985.

I/10 M/E: Werke · Artikel $\cdot$ Entwürfe. Juli 1849 bis Juni 1851 [Obras · artigos · rascunhos. De julho de 1849 até junho de 1851]. 1977.

I/11 M/E: Werke · Artikel $\cdot$ Entwürfe. Juli 1851 bis Dezember 1852. (Revolution and Counter Revolution, Der 18. Brumaire, Die großen Männer des Exils, Enthüllungen u. a.) [Obras · artigos · rascunhos. De julho de 1851 a dezembro de 1852. (Revolução e contrarevolução, O 18 Brumário, Os grandes homens do exílio, Revelações etc.)]. 1985.

\footnotetext{
${ }^{9}$ Substituído, mais tarde, pelo Arquivo Público Russo de História Política e Social.

${ }^{10}$ Eles foram substituídos pelo volume 32 da quarta seção da MEGA2. Esse volume, lançado em 1999, contém uma relação dos livros encontrados nas bibliotecas pessoais de Marx e Engels e uma descrição das anotações e marcas deixadas neles por seus proprietários.
} 
I/12 M/E: Werke · Artikel · Entwürfe. Januar bis Dezember 1853. (Publizistik: New-York Tribune, People's Paper, Reform) [Obras · artigos · rascunhos. De janeiro a dezembro de 1853. (Jornalismo: New-York Tribune, People's Paper, Reform)]. 1984.

I/13 M/E: Werke · Artikel · Entwürfe. Januar bis Dezember 1854. (Publizistik: New-York Tribune, People's Paper) [Obras · artigos · rascunhos. De janeiro a dezembro de 1854. (Jornalismo: New-York Tribune, People's Paper)]. 1985.

I/14 M/E: Werke · Artikel · Entwürfe. Januar bis Dezember 1855. (Publizistik: New-York Tribune, Neue Oder-Zeitung) [Obras · artigos · rascunhos. De janeiro a dezembro de 1855. (Jornalismo: New-York Tribune, Neue Oder-Zeitung)]. 2001.

I/18 M/E: Werke • Artikel · Entwürfe. Oktober 1859 bis Dezember 1860. (Herr Vogt u. a.) [Obras . artigos · rascunhos. De outubro de 1859 a dezembro de 1860. (Herr Vogt etc.)]. 1984.

I/20 M/E: Werke · Artikel · Entwürfe. September 1864 bis September 1867. (Gründung und Anfangsjahre der Internationalen Arbeiterassoziation, Inauguraladresse, Die preußische Militärfrage, Value, price and profit u. a.) [Obras · artigos · rascunhos. De setembro de 1864 a setembro de 1867. (Fundação e anos iniciais da Associação Internacional dos Trabalhadores, Discurso inaugural, A questão militar prussiana, Salário, preço e lucro etc.)]. 2., unveränd. Aufl. 2003.

I/21 M/E: Werke · Artikel · Entwürfe. September 1867 bis März 1871. (Internationale Arbeiterassoziation, Geschichte Irlands, Deutsch-Französischer Krieg $u$. a.) [Obras · artigos · rascunhos. De setembro de 1867 a março de 1871. (Associação Internacional dos Trabalhadores, História da Irlanda, Sobre a guerra franco-prussiana etc.)]. 2009.

I/22 M/E: Werke · Artikel · Entwürfe. März bis November 1871. (Civil War in France, Internationale Arbeiterassoziation) [Obras · artigos · rascunhos. De março a novembro de 1871. (Guerra civil na França, Associação Internacional dos Trabalhadores)]. 1978.

I/24 M/E: Werke · Artikel · Entwürfe. Dezember 1872 bis Mai 1875. (Internationale Arbeiterassiziation, Publizistik) ) [Obras · artigos · rascunhos. De dezembro de 1872 a maio de 1875. (Associação Internacional dos Trabalhadores, Jornalismo)]. 1984.

I/25 M/E: Werke · Artikel · Entwürfe. Mai 1875 bis Mai 1883. (Kritik des Gothaer Programms, Publizistik) [Obras · artigos · rascunhos. De maio de 1875 a maio de 1883. (Crítica do programa de Gotha, Jornalismo)]. 1985.

I/26 E: Dialektik der Natur (1873-1882) [Dialética da natureza (1873-1882)]. 1985.

I/27 E: Herrn Eugen Dührings Umwälzung der Wissenschaft [A revolução da ciência pelo Senhor Eugen Dühring]. 1988.

I/29 E: Der Ursprung der Familie, des Privateigentums und des Staats. [A origem da família, da propriedade privada e do estado]. 1990.

I/30 M/E: Werke · Artikel · Entwürfe. März 1883 bis September 1886. (Ludwig Fenerbach und der Ausgang der klassischen deutschen Philosophie u. a.) [Obras · artigos · rascunhos. De março de 1883 a setembro de 1886. (Ludwig Feuerbach e o fim da filosofia clássica alemã etc.)]. 2011.

I/31 E: Werke · Artikel $\cdot$ Entwürfe. Oktober 1886 bis Februar 1891 [Obras · artigos · rascunhos. De outubro de 1886 a fevereiro de 1891]. 2002.

I/32 E: Werke · Artikel · Entwürfe. März 1891 bis August 1895 [Obras · artigos · rascunhos. De março de 1891 a agosto de 1895] 2010. 
II/1 M: Ökonomische Manuskripte 1857/58. (Grundrisse der Kritik der politischen Ökonomie) [Manuscritos econômicos de 1857-58. (Fundamentos da crítica da economia política)] 2., unveränd. Aufl. 2006. [1. Aufl. Teil 1: 1976, Teil 2: 1981.]

II/2 M: Ökonomische Manuskripte und Schriften, 1858-1861. (Zur Kritik der politischen Ökonomie u. a.) [Manuscritos e estudos econômicos, 1858-1861. (Para a crítica da economia política e outros) ]1980.

II/3.1 M: Zur Kritik der politischen Ökonomie (Manuskript 1861-1863) [Para a crítica da economia política (manuscrito de 1861-1863)]. Teil 1. 1976.

II/3.2 M: Zur Kritik der politischen Ökonomie (Manuskript 1861-1863) [Para a crítica da economia política (manuscrito de 1861-1863)]. Teil 2. 1977.

II/3.3 M: Zur Kritik der politischen Ökonomie (Manuskript 1861-1863) [Para a crítica da economia política (manuscrito de 1861-1863)]. Teil 3.1978.

II/3.4 M: Zur Kritik der politischen Ökonomie (Manuskript 1861-1863) [Para a crítica da economia política (manuscrito de 1861-1863)]. Teil 4. 1979.

II/3.5 M: Zur Kritik der politischen Ökonomie (Manuskript 1861-1863) [Para a crítica da economia política (manuscrito de 1861-1863)]. Teil 5. 1980.

II/3.6 M: Zur Kritik der politischen Ökonomie (Manuskript 1861-1863) [Para a crítica da economia política (manuscrito de 1861-1863)]. Teil 6.1982.

II/4.1 M: Ökonomische Manuskripte 1863-1867. Teil 1. (Manuskripte 1864/65 zum 1. und 2. Buch des „Kapital“", Vortrag „Value, price and profit") [Manuscritos econômicos de 1863-1867. Parte 1. (Manuscritos de 1864-65 para o primeiro e segundo livros de "O Capital". Conferência "Valor, preço e lucro")] 2. unveränd. Aufl. 2011. [1. Aufl. 1988.]

II/4.2 M: Ökonomische Manuskripte 1863-1867. Teil 2. (Manuskript 1863/65 zum 3. Buch des „Kapital“) [Manuscritos econômicos de 1863-1867. Parte 2. (Manuscritos de 1863-65 para o terceiro livro de "O Capital”)] 2. unveränd. Aufl. 2012. [1. Aufl. 1993.]

II/4.3 M: Ökonomische Manuskripte 1863-1867. Teil 3. (Manuskripte 1867-68 zum 2. und 3. Buch des „Kapital“) [Manuscritos econômicos de 1863-1867. Parte 3. (Manuscritos de 1867-68 para o segundo e terceiro livros de "O Capital”)] 2012.

II/5 M: Das Kapital. Kritik der Politischen Ökonomie. Erster Band, Hamburg 1867 [O Capital. Crítica da Economia Política. Primeiro Volume, Hamburgo 1867]. 1983.

II/6 M: Das Kapital. Kritik der Politischen Ökonomie. Erster Band, Hamburg 1872 [O Capital. Crítica da Economia Política. Primeiro Volume, Hamburgo 1872]. 1987.

II/7 M: Le Capital, Paris 1872-1875[O Capital, Paris 1872-75]. 1989.

II/8 M: Das Kapital. Kritik der Politischen Ökonomie. Erster Band, Hamburg 1883 [O Capital. Crítica da Economia Política. Primeiro Volume, Hamburgo 1883]. 1989.

II/9 M: Capital. A Critical Analysis of Capitalist Production, London 1887 [Capital. Uma análise crítica da produção capitalista, Londres 1887]. 1990. 
II/10 M: Das Kapital. Kritik der Politischen Ökonomie. Erster Band, Hamburg 1890 [O Capital. Crítica da Economia Política. Primeiro Volume, Hamburgo 1890]. 1991.

II/11 M: Manuskripte zum zweiten Buch des „Kapitals“ 1868 bis 1881 [Manuscritos para o segundo livro de "O Capital". De 1868 a 1881)]. 2008.

II/12 M: Das Kapital. Kritik der Politischen Ökonomie. Zweites Buch: Der Zirkulationsprozeß des Kapitals. Redaktionsmanuskript von Friedrich Engels 1884/1885 [O Capital. Crítica da Economia Política. Segundo Livro: o processo de circulação do capital. Manuscrito redacional de Friedrich Engels 1884/1885]. 2005.

II/13 M: Das Kapital. Kritik der politischen Ökonomie. Zweiter Band. Herausgegeben von Friedrich Engels. Hamburg 1885 [O Capital. Crítica da Economia Política. Segundo Volume. Editado por Friedrich Engels. Hamburgo 1885]. 2008.

II/14 M/E: Manuskripte und redaktionelle Texte zum dritten Buch des „Kapitals“, 1871 bis 1895

[Manuscritos e textos redacionais para o terceiro livro de "O Capital”. De 1871 a 1895)]. 2003.

II/15 M: Das Kapital. Kritik der politischen Ökonomie. Dritter Band. Herausgegeben von Friedrich Engels. Hamburg 1894 [O Capital. Crítica da Economia Política. Terceiro Volume. Editado por Friedrich Engels. Hamburgo 1894]. 2004.

Dritte Abteilung: Briefwechsel [Terceira seção: correspondência]

III/1 M/E: Briefwechsel. Bis April 1846 [Correspondência. Até abril de 1846]. 1975.

III/2 M/E: Briefwechsel. Mai 1846 bis Dezember 1848 [Correspondência. De maio de 1846 a dezembro de 1848]. 1979.

III/3 M/E: Briefwechsel. Januar 1849 bis Dezember 1850 [Correspondência. De janeiro de 1849 a dezembro de 1850]. 1981.

III/4 M/E: Briefwechsel. Januar bis Dezember 1851 [Correspondência. De janeiro a dezembro de 1851]. 1984.

III/5 M/E: Briefwechsel. Januar bis August 1852 [Correspondência. De janeiro a agosto de 1852]. 1987.

III/6 M/E: Briefwechsel. September 1852 bis August 1853 [Correspondência. De setembro de 1852 a agosto de 1853]. 1987.

III/7 M/E: Briefwechsel. September 1853 bis März 1856 [Correspondência. De setembro de 1853 a março de 1856]. 1989.

III/8 M/E: Briefwechsel. April 1856 bis Dezember 1857 [Correspondência. De abril de 1856 a dezembro de 1857]. 1990.

III/9 M/E: Briefwechsel. Januar 1858 bis August 1859 [Correspondência. De janeiro de 1858 a agosto de 1859]. 2003.

III/10 M/E: Briefwechsel. September 1859 bis Mai 1860 [Correspondência. De setembro de 1859 a maio de 1860]. 2000.

III/11 M/E: Briefwechsel. Juni 1860 bis Dezember 1861 [Correspondência. De junho de 1860 a dezembro de 1861]. 2005. 
III/12 M/E: Briefwechsel. Januar 1862 bis September 1864 [Correspondência. De janeiro de 1862 a setembro de 1864]. 2013.

III/13 M/E: Briefwechsel. Oktober 1864 bis Dezember 1865 [Correspondência. De outubro de 1864 a dezembro de 1865]. 2002.

III/30 E: Briefwechsel. Oktober 1889 bis November 1890 [Correspondência. De outubro de 1889 a novembro de 1890]. 2013.

Vierte Abteilung: Exzerpte - Notizen - Marginalien [Quarta seção: excertos, notas e marginália]

IV/1M/E: Exzerpte und Notizen. Bis 1842. (Epikurstudien, Berliner und Bonner Hefte zur Philosophie, Kunst, Religion u. a.) [Excertos e notas. Até 1842. (Estudos sobre Epicuro. Cadernos de Berlim e Bonn sobre filosofia, arte, religião etc.)]. 1976.

IV/2 M/E: Exzerpte und Notizen. (Kreuznacher Hefte u. a.) 1843 bis Januar 1845 [Excertos e notas. (Cadernos de Kreuznach etc.) De 1843 a janeiro de 1845]. 1981.

IV/3 M: Exzerpte und Notizen. Sommer 1844 bis Anfang 1847. (Feuerbach-Thesen, Pariser Hefte u. a.) [Excertos e notas. Do verão de 1844 até o início de 1847. (Teses sobre Fenerbach, Cadernos de Paris etc.)]. 1998.

IV/4 M/E: Exzerpte und Notizen. Juli bis August 1845. (Manchester Hefte 1-5 u. a.) [Excertos e notas. De julho a agosto de 1845. (Cadernos de Manchester 1-5 etc.)]. 1988.

IV/6 M/E: Exzerpte und Notizen. September 1846 bis Dezember 1847. (Gülich-Exzerpte) [Excertose notas. De setembro de 1846 a dezembro de 1847. (Excertos de Gülich)]. 1983.

IV/7 M/E: Exzerpte und Notizen. September 1849 bis Februar 1851. (Londoner Hefte I-IV) [Excertose notas. De setembro de 1849 a fevereiro de 1851. (Cadernos de Londres I-IV)]. 1983.

IV/8 M: Exzerpte und Notizen. März bis Juni 1851. (Bullion. Das vollendete Geldsystem, Londoner Hefte VII-X) [Excertos e notas. De março a junho de 1851. (Bullion. O sistema monetário perfeito, Cadernos de Londres VII-X)]. 1986.

IV/9 M: Exzerpte und Notizen. Juli bis September 1851. (Londoner Hefte XI-XIV) [Excertos e notas. De julho a setembro de 1851. (Cadernos de Londres XI-XIV)]. 1991.

IV/12 M: Exzerpte und Notizen. September 1853 bis Januar 1855. (Marx: Geschichte der Diplomatie und Geschichte Spaniens; Engels: Militaria) [Excertos e notas. De setembro de 1853 a janeiro de 1855. (Marx: História da diplomacia e História da Espanha; Engels: assuntos militares)]. 2007.

IV/26 M: Exzerpte und Notizen zur Geologie, Mineralogie und Agrikulturchemie. März bis September 1878. [Excertos e notas sobre geologia, mineralogia e química agrícola. De março a setembro de 1878]. 2011.

IV/31 M/E: Naturwissenschaftliche Exzerpte und Notizen. Mitte 1877 bis Anfang 1883. [Excertos e notas sobre ciências naturais. De meados de 1877 ao início de 1883]. 1999.

IV/32 Die Bibliotheken von Karl Marx und Friedrich Engels. Annotiertes Verzeichnis des ermittelten Bestandes. [As bibliotecas de Karl Marx e Friedrich Engels.]. 1999.

Fonte: Elaborado com base em dados colhidos junto a Berlin-Brandenburgische Akademie der Wissenschaften.

\section{RELEITURAS E CONTROVÉRSIAS A PARTIR DA NOVA MEGA}

Para concluir essa apresentação do problema, é importante notar que o Marx que está emergindo desse longo e penoso esforço de edição é, em muitos aspectos, bastante distinto da imagem que tínhamos dele até aqui e que foi forjada por gerações seguidas de adeptos e de críticos de seu pensamento. 
Antes de tudo, há que reconhecer a natureza inacabada e incompleta de sua obra, característica que deve orientar a leitura e a compreensão dos textos que nos legou. Não apenas Marx publicou pouco em comparação com o volume de manuscritos que redigiu e o esforço de pesquisa que realizou ao longo de sua vida, como é preciso reconhecer que em muitos aspectos sua obra é fragmentária e aberta, além de não concluída (Musto, 2007).

A publicação da MEGA2 tem contribuído em larga medida para explicitar essas caraterísticas da obra de Marx e, com base nisso, proporcionar novas interpretações de textos e temas consagrados. Deixando de lado qualquer pretensão de fazer uma análise detida das controvérsias envolvidas nesses esforços de reinterpretação - o que seria descabido para as dimensões e objetivos desse artigo -, apresentamos a título de sustentação do que acabamos de afirmar dois debates que ilustram de modo exemplar as implicações que a nova MEGA vem tendo para a compreensão do pensamento de Marx.

O primeiro diz respeito à Ideologia Alemã. Como é sabido, esse texto foi publicado e traduzido durante décadas no formato em que veio a público pela primeira vez, em 1932, no interior da primeira MEGA. Desde então ele foi apresentado e lido como se contivesse uma formulação mais ou menos acabada do chamado materialismo histórico, que estaria apresentado especialmente no capítulo intitulado "I. Feuerbach" ${ }^{11}$ Ocorre que o texto editado por Riazanov e, mais tarde, Adoratskij difere em muito do manuscrito deixado por Engels e Marx. Tome-se, por exemplo, a seção sobre Feuerbach: apesar de ter sido efetivamente planejada por Marx e Engels, ela jamais foi completada, como o próprio Engels reconheceu anos mais tarde, ao redigir a introdução ao seu Ludwig Feuerbach e o fim da filosofia clássica alemã, de 1888:

"I have once again ferreted out and looked over the old manuscript of 1845-6. The section dealing with Feuerbach is not completed. The finished portion consists of an exposition of the materialist conception of history which proves only how incomplete our knowledge of economic history still was at that time" (Engels apud Carver, 2010, p. 116).

$\mathrm{Na}$ verdade, partes do conteúdo do manuscrito original foram remanejadas nas primeiras edições de modo a, entre outras coisas, produzir o consagrado capítulo sobre Feuerbach a partir de vários fragmentos dispersos. Isso ficou claro durante os trabalhos de edição do volume I/5 da MEGA2, que deverá conter o material relacionado a Ideologia Alemã. A equipe encarregada desse volume publicou em 2004 um número especial do Marx-Engels-Jahrbuch ${ }^{12}$ na forma de um "volume de teste", contendo partes do manuscrito reunidas como textos independentes e

\footnotetext{
${ }^{11}$ Esse "capítulo" foi publicado pela primeira vez em 1924, em versão para o russo, e novamente em 1926, desta vez na língua original.

12 Trata-se de um periódico editado pelo IMES e associado ao projeto da MEGA2.
} 
ordenados cronologicamente, na forma em que foram deixados pelos autores. Dessa edição, resultou evidente a natureza não unitária do texto, seu caráter não apenas inacabado, como também fragmentário, o que nos obriga agora a repensar seu lugar na elaboração teórica de Marx (cf. Carver, 2010; Xiaoping, 2010).

O segundo debate que é exemplar do impacto da MEGA2 na interpretação do pensamento marxiano diz respeito a publicação dos manuscritos da crítica da economia política compostos por Marx entre 1863 e 1883 e empregados por Engels na edição dos volumes II e III de O Capital. Eles agora podem ser lidos nos volumes da segunda seção da MEGA2, que contemplou a publicação dos três volumes d'O Capital tal como foram editados e publicados no século XIX, ou seja, o texto das edições do Livro I em alemão (1867, 1872, 1883 e 1890), de suas traduções francesa (1872-75) e inglesa (1887) e as edições em alemão dos Livros II (1885 e 1893) e III (1894). Além deles, foram publicados todos os manuscritos redigidos por Marx com vistas à composição d'O Capital, além de manuscritos redigidos por Engels durante o período em que preparou a edição dos Livros II e III. As implicações desse material para a compreensão da obra econômica de Marx são expressivas.

No que diz respeito ao Livro II, Marx compôs dois rascunhos completos (em 1865 e em 1868-70) e vários manuscritos menores redigidos entre 1867 e 1881 que tratam de diferentes temas. Redigiu também um texto mais longo sobre os problemas que viriam a ser abordados na terceira seção, que incluem os famosos esquemas de reprodução. Comparando essas versões com o texto estabelecido por Engels, foi possível constatar que suas intervenções foram significativas, muito superiores ao que ele deixa entender no prefácio daquele livro: mudanças na estrutura, revisão de passagens do texto e da terminologia empregada etc. Tais intervenções decorreram de uma dificuldade não mencionada por Engels: o fato de que em muitas partes do manuscrito Marx estava tentando formular novas ideias sem ter ainda alcançado conclusões definitivas a respeito dos problemas em questão (Hecker, 2009, p. 25).

Quanto ao Livro III, a comparação dos manuscritos com o volume editado revela problemas semelhantes e em maior número e relevo. Além do rascunho mais ou menos completo redigido por Marx em 1864-65, podemos agora consultar os vários manuscritos sobre o mais-valor e o lucro, sobre os fatores que regem a taxa de lucro e sobre a renda diferencial, escritos em diferentes graus de elaboração entre 1867-68 e 1881. Novamente, o que salta aos olhos é o fato de que em muitas questões a análise permaneceu aberta, sem que Marx emitisse conclusões definitivas. Por um lado, ele não parecia satisfeito com a apresentação do manuscrito de 1864-65 , tendo redigido outros rascunhos para as seções iniciais em que explorou uma sequência alternativa para a apresentação dos conceitos de mais valor, lucro e preço de custo. Em outros manuscritos, dedicou-se a estudar as leis que regem o movimento da taxa de lucro, explorando em inúmeros exercícios matemáticos os efeitos de variações no valor do capital variável e constante, na taxa de mais valor etc. ${ }^{13}$ Além disso, sabemos que Marx também não estava satisfeito com a seção do

${ }^{13}$ Esses manuscritos foram publicados no volume II.4.3 da MEGA2. 
manuscrito de 1864-65 sobre a renda fundiária. Se não chegou a preparar um texto alternativo que completasse o tratamento dado naquela versão, podemos agora conhecer seus estudos sobre a renda e a propriedade da terra através do conteúdo dos cadernos de excertos que preparou e dos comentários feitos ao longo de sua correspondência (Roth, 2009, pp. 33-7).

Finalmente, os temas do crédito e dos juros, abordados na quinta seção do Livro III, e, em estreita conexão com eles, a discussão sobre as crises, também permaneceram em aberto no manuscrito de 1864-65. Como o próprio Engels reconheceu no seu prefácio de 1890 , o texto do manuscrito relativo àquela seção alterna trechos em que temos uma apresentação clara dos temas abordados com outros em que ideias e observações são anotadas ainda sem qualquer preocupação com seu encadeamento com o restante do argumento, revelando muito mais um documento de trabalho do que um manuscrito acabado. No que diz respeito ao crédito, Marx parece hesitar entre a intenção manifesta no início do manuscrito, de não fazer uma análise do sistema de crédito e seus instrumentos - porque, àquela altura, esses temas estariam além do plano da obra -, e o desejo expresso alguns anos mais tarde de fazer da quinta seção justamente uma seção sobre o crédito (Roth, 2009, p. 37). ${ }^{14}$ Além disso, a partir desse período, e em conexão com seus estudos sobre a crise de 1866, ele reuniu uma grande quantidade de extratos de jornais e notas de leitura sobre os movimentos do crédito, material que pretendia empregar numa futura revisão do manuscrito do Livro III (Paula et al., 2013, 2015; Heinrich, 2007, p. 198).

Esses e outros aspectos remetem à polêmica sobre o trabalho de edição d' $O$ Capital feito por Engels. ${ }^{15}$ A natureza fragmentária dos manuscritos compostos para o Livro III exigiu de Engels o acréscimo de algumas passagens e a supressão de outras, a inclusão de títulos e a divisão de textos, a transposição de partes do texto e seu rearranjo de modo a torná-lo publicável. Parte significativa dessas alterações não foi, porém, indicada na versão publicada e, desse modo, passaram até hoje por decisões que teriam sido tomadas por Marx. ${ }^{16} \mathrm{Na}$ verdade, tais mudanças traduzem a interpretação de Engels como editor e testamenteiro literário de Marx sobre o sentido adequado do seu texto. A consulta aos manuscritos revela, entre-

\footnotetext{
${ }^{14}$ Para Heinrich (1996-1997, pp. 462-3) a decisão de abordar ou não o sistema de crédito dizia respeito ao problema nada trivial de saber se as leis que regulam o seu movimento poderiam ser tratadas no nível de abstração d'O Capital ou se dependeriam de elementos histórico-institucionais que tornariam impraticável conceber uma teoria geral do crédito.

${ }^{15}$ Velha polêmica, diga-se de passagem. Gide e Rist (1909, p. 520) já apontavam a dificuldade de distinguir precisamente a natureza e dimensão da participação de Engels na obra de Marx: "Não devemos nos esquecer, ao lado de Karl Marx, de seu inseparável amigo e colaborador Friedrich Engels, que no entanto viveu modestamente à sombra do mestre. Contudo, foi ele que colaborou no famoso Manifesto Comunista de 1848 e que, depois da morte de Marx, recolheu e publicou fielmente os três volumes de suas obras póstumas. É muito difícil saber qual é a parte que lhe cabe na obra de Marx, mas é provável que ela não seja negligenciável”.

${ }^{16}$ Heinrich (1996-1997, p. 456) chega a afirmar que "the comparison of the original manuscript with Engels' edition [...] shows that there are modifications to the original text on practically each page that have not been indicated".
} 
tanto, a existência de outras possibilidades de leitura e, sobretudo, aponta a natureza incompleta e aberta do tratamento que Marx deu a questões como a teoria das crises ou o papel do crédito e do juro, diversas em mais de um sentido da impressão sugerida pelo texto editado (cf. Müller et al., 2002; Vollgraf e Jungnickel, 2002; Roth, 2009, 2010; Heinrich, 1996-1997, 2007, 2013).

É importante ressaltar que o que está em questão não é um juízo depreciativo sobre o trabalho de Engels, seja pelo fato de que os padrões de edição da época eram muito mais flexíveis do que os de uma edição histórico-crítica moderna, seja porque seu objetivo era o de concluir o trabalho de edição para proporcionar ao movimento socialista uma arma teórica decisiva para a disputa política, o que exigia interpretar as passagens que no manuscrito estavam longe de concluídas, ou que tinham sido apenas esboçadas (Heinrich, 2007, p. 201). De fato, "we must not forget that it was an incredible achievement to publish this manuscript, of which Marx had once said in a letter to Engels that nobody at all could publish it in a readable form except for he himself (letter on February 13, 1866)" (Heinrich, 1996-1997, pp. 464-5). O que importa é que uma leitura que pretenda reconstituir o sentido do argumento não precisa mais se contentar com a versão editada do Livro III, mas deve recorrer aos manuscritos deixados por Marx - e finalmente publicados na MEGA2 - para buscar estabelecer o sentido último e as possibilidades deixadas em aberto pelo texto.

\section{CONCLUSÃO}

Em resumo, a publicação da MEGA2 tem oferecido a oportunidade conhecer manuscritos até aqui inéditos e que nos revelam um Marx crítico das limitações de seu próprio trabalho e permanentemente insatisfeito diante do que já havia escrito. Ele permaneceu sempre disposto a rever e atualizar suas formulações, a mergulhar em novos materiais empíricos e deles extrair consequências teóricas, o que explica em boa medida o caráter provisório e fragmentário de muitas de suas elaborações. O mesmo pode ser dito em relação às pesquisas em curso sobre outros textos, cuja publicação também está prevista pela MEGA2, mas que ainda permanecem inéditos, como os Exzerpthefte. Investigações preliminares desse material têm mostrado que eles podem oferecer sugestões interessantes para a compreensão do método de investigação adotado por Marx e para o entendimento de suas pesquisas sobre o crédito e as crises econômicas, apontando elementos que pretendia tratar em revisões posteriores do manuscrito d'O Capital (Paula et al., 2013).

No contexto contemporâneo, em que as obras de Marx estão livres do ônus de proporcionar suporte ideológico para regimes autoritários e em que uma nova crise das economias capitalistas revela a atualidade de seu pensamento, a publicação da MEGA2 abre novas possibilidades de leitura daquelas obras. São possibilidades que estão longe de terem sido plenamente exploradas e compreendidas, mas os primeiros resultados têm se mostrado promissores e é a partir deles que os esforços de interpretação do pensamento de Marx devem avançar ao longo dos próximos anos. 


\section{REFERÊNCIAS BIBLIOGRÁFICAS}

Alcouffe, Alain; Wells, Julian (2009). Marx, maths, and MEGA 2. Trabalho apresentado na $13^{\text {th }}$ Annual Conference of the European Society for the History of Economic Thought. Thessaloniki: ESHET.

Anderson, Kevin B. (2010). Marx at the Margins: On Nationalism, Ethnicity, and Non-Western Societies. Chicago: The University of Chicago Press.

Bellofiore, Riccardo (1999). "Lavori in corso". Common Sense - Journal of the Edinburgh Conference of Socialist Economists, v. 22, pp. 43-60.

Bellofiore, Riccardo; Fineschi, Roberto (2009). Introduction. In Bellofiore e Fineschi, Re-reading Marx: New Perspectives After The Critical Edition. New York: Palgrave Macmillan.

Carver, Terrell (2010). “The German ideology never took place”. History of Political Thought, v. 31 (1): 107-127.

Cerqueira, Hugo (2010). “David Riazanov e a edição das obras de Marx e Engels”. Economia, v. 11 (1): 199-215.

Fineschi, Roberto (2008). Un Nuovo Marx: Filologia e Interpretazione dopo la Nuova Edizione Storico-critica $\left(\mathrm{MEGA}^{\circledR}\right)$. Roma: Carocci.

Gide, Charles; Rist, Charles.(1909) Histoire des Doctrines Economiques depuis les Physiocrates jusqu'a nos Jours. Paris: Librarie de la Société du recueil J.-B. Sirey.

Hecker, Rolf (2002). "La seconda sezione della MEGA ${ }^{\circledR}$ : verso Il completamento". In: Alessandro Mazzone (ed.). MEGA ${ }^{\odot}$ : Marx ritrovato. Roma: Media Print, pp. 49-67.

HeCKer, Rolf (2009). "New perspectives opened by the publication of Marx's manuscripts of Capital, vol. II”. In: Riccardo Bellofiore; Roberto Fineschi. Re-reading Marx: new perspectives after the critical edition. New York: Palgrave Macmillan.

Hecker, Rolf (2010). "The history and meaning of the MEGA project from its inception until 1990". Marxism 21, v. 20: 281-292.

HeInRICH, Michael (1996-1997). "Engels' edition of the third volume of Capital and Marx's original manuscript” Science \& Society, v. 60 (4): 452-466.

Heinrich, Michael (2007). "Review of "Karl Marx. Das Kapital. Kritik der politischen Ökonomie. Dritter Band, Hamburg, 1894“, In Karl Marx, Friedrich Engels, Gesamtausgabe (MEGA $\left.{ }^{\odot}\right)$. Zweite Abteilung. Band 15”. Historical Materialism, v. 15: 195-210.

HeInRICH, Michael (2013). "Crisis theory, the law of the tendency of the profit rate to fall, and Marx's studies in the 1870s". Monthly Review, v. 64 (11): 15-31.

Новsbawn, Eric (1983). “A fortuna das edições de Marx e Engels”. In: Eric Hosbawn et alli. O Marxismo no Tempo de Marx. (História do marxismo, vol. 1), Rio de Janeiro: Paz e Terra.

Новsваwм, Eric(2011). “A influência do marxismo”. In: Eric Hosbawn. Como Mudar o Mundo: Marx e o marxismo 1840-2011. São Paulo: Companhia das Letras.

Müller, Manfred; Jungnickel, Jürgen; Lietz, Barbara; Sander, Christel; Schnickmann, Artur (2002). "General commentary to Marx's manuscript of Capital, Book 3." International Journal of Political Economy, v. 32 (1): 14-34.

Musto, Marcello (2007). “The rediscovery of Karl Marx”, International Review of Social History, v. 52: 477-498.

Musto, Marcello (2010). "Marx is back: the Marx-Engels-Gesamtausgabe (MEGA) project”, Rethinking Marxism, v. 22 (2): 290-291.

Paula, João Antonio de; Cerqueira, Hugo da Gama; Cunha, Alexandre M.; Suprinyak, Carlos E.; De Deus, Leonardo G.; Albuquerque, Eduardo da Motta (2013). "Notes on a crisis: the Exzerpthefte and Marx's method of research and composition". The Review of Radical Political Economics, v. 45 (2): 162-182.

Paula, João Antonio de; Cerqueira, Hugo da Gama; De Deus, Leonardo G.; Suprinyak, Carlos E.; Albuquerque, Eduardo da Motta (2015). Marx, the Notebooks on the Crisis of 1866 and Structural Changes in Capitalism: investigating financial innovation and stock exchanges. (Texto para Discussão, n. 515), Belo Horizonte, Cedeplar-UFMG. 
Rотн, Regina (2009). "Karl Marx original manuscripts in the Marx-Engels-Gesamtausgabe (MEGA): another view on Capital”. In: Riccardo Bellofiore; Roberto Fineschi. Re-reading Marx: new perspectives after the critical edition. New York: Palgrave Macmillan.

Rотн, Regina (2010). "Marx on technical change in the critical edition". The European Journal of the History of Economic Thought, v. 17 (5): 1223-1251.

RoJAHn, Jürgen (1998). Publishing Marx and Engels after 1989: the fate of the MEGA. (Disponível em $<$ http://www.iisg.nl/imes/documents/mega-e98.pdf>.

TAKenAga, Susumu (2009). Editorial work of MEGA2 in Japan. Trabalho apresentado na 13th Annual Conference of the European Society for the History of Economic Thought. Thessaloniki: ESHET.

Thomas, Paul (1991). Critical reception: Marx then and now. In: Terrel Carver (ed.). The Cambridge companion to Marx. Cambridge: Cambridge U.P.

VollgrafF, Carl-Erich; Jungnickel, Jürgen (2002). "Marx in Marx's words”? On Engels's edition of the main manuscript of Book 3 of Capital". International Journal of Political Economy, v. 32 (1): 35-78.

XIAOPING, Wei (2010). Rethinking historical materialism: the new edition of The German Ideology. Science \& Society, v. 74 (4): 489-508.

Zapata, R. (1985). "La publication des oeuvres de Marx après sa mort: 1883-1935“. In: Labica, G. (ed.), 1883-1983 L'Oenvre de Marx, un Siècle Après. Paris: PUF. 